\title{
Can The Arterial Clamping Method Be Used Safely Where The Tourniquet Cannot Be Used?
}

\section{Ozgur Erdogan ( $\nabla$ drozgurerdogan@gmail.com )}

Health Sciences University Haydarpasa Numune Training and Research Hospital https://orcid.org/0000-0002-6703-3881

\section{Volkan Gurkan}

Bezmialem University Faculty of Medicine

\section{Cavide Sonmez}

Bezmialem Vakif University: Bezmialem Vakif Universitesi

\section{Tunay Erden}

Bezmialem University Faculty of medicine

\section{Sezen Atasoy}

Istanbul Universitesi Cerrahpasa

\section{Fatih Yildiz}

Bezmialem University Faculty of Medicine

\section{Bekir Inan}

Bezmialem University Faculty of medicine

Adile Adilli

Bezmialem University Faculty of medicine

\section{Research article}

Keywords: tourniquet, clamp, hemorragia, artery, vein, injury

Posted Date: October 21st, 2020

DOI: https://doi.org/10.21203/rs.3.rs-93183/v1

License: (a) (1) This work is licensed under a Creative Commons Attribution 4.0 International License. Read Full License 


\section{Abstract}

Background: Vascular clamp application is widely used in visceral organ surgery to ensure bleeding control. This raises the question: why not use clamping in tumor resection or revision surgery where not suitable for tourniquet. This experimental animal study aimed to compare the arterial clamp and tourniquet applications regarding their histologic effect and also inflammatory response at molecular level, on the artery, vein, nerve and muscle tissues.

Methods: Twenty-one rabbits were divided into three groups (group I: proximal femoral artery clamp; group II: proximal thigh tourniquet, and group III: control group). In the clamp group, the common femoral artery was clamped with a microvascular clamp for 2 hours. In the tourniquet group, a 12-inch cuff was applied to the proximal thigh for 2 hours with $200 \mathrm{mmHg}$. The common femoral artery and vein, femoral nerve, rectus femoris, and tibialis anterior muscles were excised and analysed in all groups.

Results: Artery and vein total injury scores were higher in the clamp and tourniquet groups relative to the control group ( $p \leq 0.001$ and $p=0.007$, respectively). No statistical difference was found between the clamp and tourniquet groups in terms of arterial, vein, muscle and nerve injury.

Conclusions: This experimental study can give an idea that arterial clamp application can be performed with the help of a vascular surgeon in hemorrhagic limb surgeries where not suitable for tourniquet application, resulting in close to tourniquet vessel injury rates but without tourniquet related complications.

\section{Introduction}

Blood loss can occur in any surgical procedure. However, certain types of surgery are associated with higher amount of blood loss that requires transfusion. Some of these procedures are kidney, hepatic, orthopedic, and vascular operations. ${ }^{[1]}$ In the orthopaedic field, especially malignant tumor surgery of the extremity may result in severe blood loss, which cause difficulties in the dissection of the tumor and neurovascular structures, and consequently prolonged surgical times, excessive blood transfusions and transfusion related complications. Tourniquet application may solve this problem, however its use become impossible if the surgical field is very proximal, where arterial clamp use can be effective. It should be noted that tourniquet use can be dangerous and in some instances might be contraindicated. ${ }^{[2]}$ Also, there are controversies about the appropriate application time and pressure. Moreover, severe neurologic and muscular damages related to the use of a tourniquet have been reported. ${ }^{[3]}$

In radical surgical procedures, arterial clamp application through an additional small incision and vascular dissection, which can quickly close and open the blood supply, can solve these problems. However, orthopaedic surgeons are mostly not familiar with the arterial clamp use or they are not sure about its reliability and/or safety. The literature about arterial clamp use in the malignant tumor surgery of the proximal part of the extremity is lacking. This raises the question: why not use clamping in tumor resections or revision surgeries where not suitable for tourniquet. This is the main question motivating the 
current work. The current study aims to investigate effectiveness and safety of the arterial clamps in terms of its possible damage to the arterial wall. Hypothesis of this study was that tourniquet use has less adverse effect on the arterial wall than the direct application of the arterial clamp.

\section{Materials And Methods}

According to the guide for the care and use of the laboratory animals principles, animal rights were protected in this study. A local ethical committee approved this animal study (2016/154). In the study design, $21 \mathrm{New}$ Zealand male, white rabbits (8 months old, mean weight $3000 \mathrm{~g}$, range 2.6-3.4 kg) were obtained from a private farm, by veterinary faculty authority.

All 21 rabbits were used in this study. Rabbits were divided into three groups of 7 each: group I received a proximal femoral artery clamp; group II received a proximal thigh tourniquet, and group III was the control group. The rabbits were prepared in the supine position after anaesthesia using $2 \mathrm{mg} / \mathrm{kg}$ of intramuscular diazepam and $40 \mathrm{mg} / \mathrm{kg}$ ketamine, and they were draped after shaving and cleaning their skin with betadine. In order not to affect Tumor Necrosis Factor Alpha (TNF-a) values, only one limb was used in all subjects. A total of 21 specimens were used.

\section{Surgical set up:}

\section{Clamp group:}

In the clamp group, a proximal incision was made anteromedially over the femoral neurovascular margin, the skin, subcutaneous tissue, and deep fascia were incised. After dissecting the muscles and exposing the neurovascular bundle, the femoral artery was dissected and clamped with a microvascular clamp (Biemer vessel clip, 7-mm jaw length, closing force $30 \mathrm{G}, \mathrm{MCl}-47-104$, Medical Care Instruments, Manchester, UK). The area where the clamp was applied was referred to as the "middle". The location 1$\mathrm{cm}$ proximal was denoted as 'proximal', the location 1-cm distal was denoted as 'distal', and both were marked with 4.0 vicryl. At the same level, the common femoral vein, femoral nerve, and rectus femoris muscle segments were marked in the same fashion. The clamping time was $2 \mathrm{~h}$. At the end of $2 \mathrm{~h}, \mathrm{a}$ longitudinal incision was made on the anterolateral side of the leg, and a 5-cm segment of tibialis anterior muscle was excised. From the marked lines, the common femoral artery and vein, femoral nerve and rectus femoris muscle were excised. The samples were sent to the pathology laboratory to complete histologic analyses. The animals were euthanized after the procedure.

\section{Tourniquet group:}

In the tourniquet group, a "Blue 12 inch for child" (Reference No: 20-54-710, VBM Medizintechnik GmbH, Sulz am Neckar, Germany) tourniquet was used. The standard tourniquet time for all subjects was $2 \mathrm{~h}$, and the pressure was $200 \mathrm{mmHg} .{ }^{[4]}$ The proximal and distal borders of the cuff were marked with a tissue pen. After $2 \mathrm{~h}$, the tibialis anterior muscle section was excised as with the clamp group. The tourniquet 
was released and removed, then the common femoral artery and vein, femoral nerve, and rectus femoris muscle were excised from the previously marked cuff margins.

\section{Control group:}

In the control group, no clamp or tourniquet application was made. A longutidinal incision was made on the anterolateral side of the crus. A 5-cm length of tibialis anterior muscle was excised. A longitudinal anteromedial incision was made over the femoral neurovascular bundle. Neurovascular bundle and rectus femoris muscle were marked with 4.0 vicryl suture rope from the proximal and distal borders. Then, the bundle and rectus femoris muscle were excised. Histological examination of the common femoral artery and vein, femoral nerve, rectus femoris and tibialis anterior muscle were performed. Animals were euthanised (Figure 1-2).

\section{Histological Analyses:}

Areas with significant histological findings were evaluated. In the clamp group, the arterial specimen was divided into three groups as proximal, middle (clamp area) and distal. The purpose of this distinction was to compare the normal tissue in the proximal part of the ischemic area, the damage to the arterial wall in which the clamp was applied, and the changes due to ischemia in the distal of the clamp.

In the tourniquet group, the artery sample was divided into three groups likewise. The purpose of this distinction was to evaluate the effect of pressure difference on the tissues between the proximal and the middle of the tourniquet cuff and to examine the effect of ischemia on the distal side.

In both the tourniquet and the clamp groups, the vein, nerve and muscle tissues were divided into three groups as proximal, middle and distal. In the clamp group, the purpose of this distinction was to evaluate the tissue injury caused by surgical dissection. In the tourniquet group, the purpose of this distinction was to evaluate the effect of pressure difference between the proximal and middle of the tourniquet cuff and to examine the effect of ischemia on the distal side. The tibialis anterior muscle tissue was examined in all three groups to compare the ischemic injury in the distal of extremity. Connective and adipose tissues have not been evaluated because significant light microscopic findings are not expected with short-term trauma and hypoxia in these kind of tissues.

Six slides for vessels and three slides for nerve and muscles were obtained per sample. Samples from each group were fixed with $10 \%$ neutral-buffered formalin for one day and processed for standard paraffin embedding. Serial sections (4- $\mu$ m thick slices) were cut by using a microtome. All of the sections were stained with hematoxylin and eosin (H\&E) and vessel sections with Elastic Van Gieson stain (Ventana) for light microscopic examination (Nikon-Eclipse-80i-DS-Ri1). An automatic device (Ventana, Benchmark XT) was used for histochemical staining. The photographs were captured with a digital camera (Nikon-Eclipse-80i-DS-Ri1). The pathologist - who was blinded to the slide numbers and the groups - examined the slides for tissue damage, including sections from the tibialis anterior and rectus femoris muscles, the femoral nerve, and the femoral artery and the vein: (a) Skeletal muscle - 
Degeneration and inflammation were evaluated for scoring the skeletal muscle injury, semiquantitatively. Histological findings as cytoplasmic eosinophilia with loss of cytoplasmic structures, cytoplasmic vacuolation, swelling, loss of the striation, fragmentation and rupture were used for scoring muscle degeneration; [score 1, findings are mild and focal, score 2, moderate and at some areas, score 3, severe and common. Following criteria was used for inflammation, score 0, no inflammation, score 1, mild inflammation, score 2, moderate inflammation and score 3 severe inflammation]. Both scores were added and total muscle injury scores were calculated for each groups. (b) Nerve Tissue - Degenerative changes in peripheral nerve fibres were determined semiquantitatively according to oedema and axonal degeneration with light microscopy. If the findings are mild, the score is 1 , the moderate, score is 2 , and the severe, score is 3 . Light microscopy can give limited information without electron microscopy findings. Essentially we did not expect serious damage to the nerve as the clamp or tourniquet is applied for a short time. (c) Vessels: The arterial injury was scored using the following criteria in Table 1. The endothelial injury was scored using the same method applied for the arteries and for veins. The venous intimal plaque was also evaluated. Using a quantitative approach, intact endothelium in the $500 \mu \mathrm{m}$ segment was assessed. Vessel injury parameters were NEC (number of endothelial cells), SEI (score of endothelial injury), the continuity of the internal elastic lamina SLEI (score of lamina elastica interna injury) and STMSMV (score of tunica media smooth muscle vacuolation).

\section{Western blot analysis:}

Tissue samples from each group were snap frozen in liquid nitrogen and stored at $-80^{\circ} \mathrm{C}$. Being a key regulator for tissue injury TNF-a and also for loading control, beta-actin antibodies were used for analysis and blots were determined using imaging system (Vilber FUSION FX, France).

\section{Statistical methods:}

Power Analysis was made before the experimental set up to determine the number of animals. The difference between the groups was predicted using Margovsky et al. "Area of endothelial damage" values.

[5] The effect size (d) was 2.19 in the calculation for obtaining $80 \%$ power at the $a=0.05$ level. Accordingly, it has been determined that there should be at least seven members in the groups. Descriptive statistics are used to define continuous variables (mean, standard deviation, minimum, median, maximum). Comparisons of independent variables with normal distribution were performed using the Student's t-test. Comparisons of two independent and non-normal distributions were performed using the Mann-Whitney $\mathrm{U}$ test. The Chi-Square test (or Fisher Exact test at appropriate locations) was used to examine the relationship between categorical variables. The statistical significance level was determined as 0.05. The analysis was performed using MedCalc Statistical Software version 12.7.7 (MedCalc Software BVBA, Ostend, Belgium) and ordinary one-way ANOVA was performed using GraphPad Prism version 7.0c (GraphPad Software, La Jolla California USA).

\section{Results}

Artery: 
In the clamp group, the NEC values were lower, the SEI, SLEI, TMSMV and Total Score values were higher than the control group ( $p \leq 0.001, p \leq 0.001, p \leq 0.001, p=0.004$ and $p \leq 0.001$, respectively). In the tourniquet group, the NEC values were lower, the SEI, SLEI, TMSMV and Total Score values were higher than the control group $(p=0.007, p \leq 0.001, p=0.004, p=0.008$ and $p \leq 0.001$, respectively). When the clamp and tourniquet groups were compared with each other, no difference was found for all vascular parameters (Figure 1c-d) (Table 2).

\section{Vein:}

In the clamp group, the NEC values were lower and SEI values were higher than the control group ( $p \leq 0.01$ and $p=0.055$, respectively). In the tourniquet group, the NEC values were lower, SEI and SLEI values were higher than the control group ( $p \leq 0.01, p=0.023$ and $p=0.034$, respectively). No difference was found between the clamp and tourniquet groups according to all vascular parameters (Table 3).

\section{Nerve and Muscle:}

There was no difference between the clamp and tourniquet groups regarding femoral nerve injury scores, rectus femoris and tibialis anterior degeneration, inflammation, and total injury scores $(p=0.533, p=0.876$, $p=0.604, p=0.756$, respectively).

\section{Protein analysis:}

Protein levels were evaluated by Western blotting. The samples were normalised for the beta-actin level. The bands were analysed by densitometry and normalised using Image $\mathrm{J}$ Software (National Institutes of Health, USA). Statistical analysis was carried out by ordinary one-way ANOVA using GraphPad Prism version 7.0c (GraphPad Software, La Jolla California USA) and no statistically significant difference was found between the groups for TNF-a values $(p=0.1712)$ (Figure 3).

\section{Discussion}

To the best of our knowledge about English literature, this is the first study comparing the tourniquet and arterial clamping. This study found no significant difference between tourniquet and clamp methods regarding histologic and inflammatory response on the vessel. Therefore, the clamp method could be used in orthopedic oncologic, trauma and revision hip joint surgery that are unsuited to a tourniquet application. External iliac artery or axillary artery can be clamped by a vascular surgeon at the beginning of a revision joint surgery or the resection of proximal limb tumor. With careful vessel dissection and the minimum pressure required for occlusion, clamp-related complications could be avoided. Interrupting blood flow using an arterial clamp or a tourniquet is associated with hemodynamic changes, and response leads to inflammation and triggers pathophysiological processes. ${ }^{[6]}$ Zammert et al. reported that with the arterial clamp application, TNF-a plays a crucial role in the hemodynamic changes and is associated with tissue injury. ${ }^{[7]}$ Although the mechanism of endotoxins after clamping is unclear, Caty et al. showed that TNF-a is involved in the initiation of injury. ${ }^{[8]}$ Our study indicates that increased TNF-a 
protein expression is associated with the tourniquet groups; although, when all of the groups were compared with each other, no significant differences were found (Fig. 3). In this scope, our findings suggest that clamp application is favorable as compared to the use of a tourniquet. Longer tourniquet time and higher inflation pressure are associated with higher complication risk. ${ }^{[9]}$ Also, higher age and comorbidities (e.g., trauma, peripheral vascular disease, hypertension) elevate the rate of complications. [10] Thus, debates continue about the safety limits associated with pressure and duration. However, most authors suggest that $1.5-2 \mathrm{~h}$ with $200-250 \mathrm{mmHg}$ inflation pressure is appropriate for healthy, normotensive patients. ${ }^{[4]}$ When these safety limits are exceeded, complications might be encountered. ${ }^{[2]}$ Another parameter that affects the pressure is the cuff width. The cuff should be as wide as possible, and it should not encroach upon the surgical site. ${ }^{[2]}$ Contrary to this general belief, a report suggests that muscle damage increases with wide cuffs. ${ }^{[11]}$ There are several reports regarding nerve injury related to the use of tourniquets. ${ }^{[12,13]}$ Nerve tissue is more sensitive to mechanical pressure than muscles, and injury is severe at the proximal and distal edges because of shear stress. ${ }^{[9,13]}$ There is a strong correlation between mechanical pressure duration and nerve injury. Even below 30 min of inflation time, paralysis has been reported. Also, after each $30 \mathrm{~min}$ increase in duration, there is a three-fold increase in neurological complications. ${ }^{[13]}$ Muscle tissue is more sensitive to prolonged ischemia than the nerve tissue. Moreover, the injury is severe beneath the cuff. ${ }^{[4]}$ Animal studies have shown that tourniquets are related to decreased muscle force beneath and distal to the cuff and are directly proportional to cuff pressure. ${ }^{[14]}$ Contrary to nerve and muscle complications, vascular complications due to tourniquet use are rare. However, some reports suggest the opposite. For example, Rush et al. found that direct pressure can cause fracture of a plaque formation or thrombosis in atherosclerotic vessels. ${ }^{[15]}$ DeLaurentis et al. suggested not to use tourniquets if there is a femoropopliteal aneurysm, femoral-popliteal bypass or calcification. They also concluded that ischemic pressure necrosis is an additional mechanism of injury. ${ }^{[16]}$ Another report recommends avoiding tourniquet use with poor distal pulses, capillary return or calcified vessels near the application field. ${ }^{[17]}$ However, the reasons for this suggestion (whether because of tourniquet-caused fractures or distortion-traction during surgery) are unclear. ${ }^{[18]}$ Although various types of skin protection paddings have been produced, skin injury can be encountered with rates of $0.04-0.1 \%$. [19]

As a result, tourniquet application has several disadvantages. Nerve and muscle injury are common complications and can occur even with short inflation times. The complication rates increase when the applied pressure is not adjusted to systemic blood pressure, extremity diameter, and cuff width. Tourniquets also require regular calibration, and incorrect calibrations can cause serious complications. Vessel complications might be less rare, but additional nerve, muscle, and skin complications should be noted.

No international quantitative unit can repeatedly be used in experimental and clinical studies to measure clamp pressure. ${ }^{[20,21]}$ In an experimental study, to standardize the clamp pressure between the subjects, the authors noted the lowest notch number at which the clamp did not slip on the vessel but provided 
transient occlusion. ${ }^{[5]}$ In the same manner, to standardize the pressure, we used the same micro clamp which is the smallest available - to occlude the vessel for all subjects.

There are also experimental studies examining vessel damage due to clamp application. ${ }^{[5]}$ In an experimental study, four DeBakey vascular clamps were applied on four adult sheep's eight carotid arteries for durations of $15,30,45$, and 60 min, respectively. A significant and ongoing increase in endothelial damage was seen at $15 \mathrm{~min}$; the damage was maximal after $30 \mathrm{~min}$. The authors concluded that there are four variables to determine the force needed to occlude a vessel: vessel diameter, blood pressure, vessel elasticity, and blade contact area. ${ }^{[5]}$ The severity of injury varies by duration, pressure, intraluminal flow pattern, plaques and vessel elasticity. ${ }^{[5]}$

There were some limitations associated with this study. First, this study did not include a group of participants that were allowed to live after the study (to investigate the late histological changes for both the tourniquet and clamp application). This group of subjects could have provided more information about the amount of repair possible over time and would also shed light on clinical adaptations. However it is unclear how long subjects should be kept alive to assess long-term effects healthily. Another limitation of the study was that we were unable to compare or equalize the pressures of the tourniquet and the clamp.

In conclusion, this study found no statistical difference between tourniquet and clamp methods regarding vessel injury. The tourniquet application is not ideal for the proximal field of extremities. In addition, they might cause vessel complications in the presence of underlying vascular disease. Also, skin, muscle and nerve complications could be encountered. The complication rates increase when the applied pressure is not adjusted to systemic blood pressure and extremity diameter. When using clamp in clinical practice, iatrogenic vessel injuries may be encountered during vascular dissection and may require peroperative vascular surgeon consultation. However, clamp-related complications could be avoided with careful dissection and the minimum pressure required for occlusion. Arterial clamp method can be safe and useful -without tourniquet related complications- for proximal of the extremities, where there is not enough space for tourniquet.

\section{Declarations}

Conflict of Interest: None.

Funding: Bezmialem Vakif University Scientific Research Projects supported this work's data collection. Project No: 2016/17.

Ethics approval and consent to participate: The animal study proposal was approved by the local ethical committee and local animal experiment ethics committee (HADYEK) of the Bezmialem University with the permit number: 2017/21. 
Availability of data and materials: The datasets used and/or analysed during the current study are available from the corresponding author on reasonable request.

\section{Authors' contributions:}

VG: Drafting the article critical revision of the article and final approval of the version to be published.

OE: Conception or design of the work, data collection and data analysis with interpretation.

CS: Critical revision of the article and final approval of the version to be published.

TE: Conception or design of the work.

SA: Data analysis with interpretation.

FY: Critical revision of the article

BI: Data analysis with interpretation.

AA: Data analysis with interpretation.

All authors read and approved the final manuscript.

\section{Acknowledgments:}

Bezmialem Vakif University Scientific Research Projects supported this work's data collection. Project No: 2016/17. Authors would like to thank Neslihan Gokmen for assistance with these valuable statistics used in this report.

\section{References}

1. Ohmori T, Matsumoto T, Kitamura T, Tamura R, Tada K, Inoue T et al. Scoring system to predict hemorrhage in pelvic ring fracture. Orthop Traumatol Surg Res 2016 Dec;102(8):1023-28.

2. Saied A, Ayatollahi Mousavi A, Arabnejad F, Ahmadzadeh Heshmati A. Tourniquet in surgery of the limbs: a review of history, types and complications. Iran Red Crescent Med J 2015;17(2):9588.

3. Duignan KM, Lamb LC, DiFiori MM, Quinlavin J, Feeney JM. Tourniquet use in the prehospital setting: Are they being used appropriately?.Am J Disaster Med 2018;13(1):37-43.

4. Pedowitz RA. Tourniquet-induced neuro-muscular injury. A recent review of rabbit and clinical experiments. Acta Orthop Scand Suppl 1991;245:1-33.

5. Margovsky Al, Lord RS, Chambers AJ. The effect of arterial clamp duration on endothelial injury: an experimental study. Aust N Z J Surg 1997;67(7):448-51.

6. Medzhitov R. Origin and physiological roles of inflammation. Nature 2008;454(7203):428-35. 
7. Zammert M, Gelman S. The Pathophysiology of Aortic Cross-Clamping. Best Pract Res Clin Anaesthesiol 2016;30(3):257-69.

8. Caty MG, Guice KS, Oldham KT, Remick DG, Kunkel SI. Evidence for tumor necrosis factor-induced pulmonary microvascular injury after intestinal ischemia-reperfusion injury. Ann Surg 1990;212(6):694-700.

9. Yin D, Delisle J, Banica A, Senay A, Ranger P, Laflamme GY, Jun J, Fernandes J. Tourniquet and closed-suction drains in total knee arthroplasty. No beneficial effects on bleeding management and knee function at a higher cost. Orthop Traumatol Surg Res 2017 Jun;103(4):583-589.

10. Kam PC, Kavanagh R, Yoong FF. The arterial tourniquet: pathophysiological consequences and anaesthetic implications. Anaesthesia 2001;56(6):534-45.

11. Chalidis BE, Kalivas E, Parziali M, Christodoulou AG, Dimitriou CG. Cuff width increases the serum biochemical markers of tourniquet-induced skeletal muscle ischemia in rabbits. Orthopedics 2012;35(8):1245-50.

12. Deloughry JL, Griffiths R. Arterial tourniquets. Continuing Education in Anaesthesia. Crit Care Pain (Indian Edition) 2009;2:64-8.

13. Horlocker TT, Hebl JR, Gali B, Jankowski CJ, Burkle CM, Berry DJ et al. Anesthetic, patient, and surgical risk factors for neurologic complications after prolonged total tourniquet time during total knee arthroplasty. Anesth Analg 2006;102(3):950-5.

14. Mohler LR, Pedowitz RA, Lopez MA, Gershuni DH. Effects of tourniquet compression on neuromuscular function. Clin Orthop Relat Res 1999;(359):213-20.

15. Rush JH, Vidovich JD, Johnson MA. Arterial complications of total knee replacement. The Australian experience. J Bone Joint Surg Br 1987;69(3):400-2.

16. DeLaurentis DA, Levitsky KA, Booth RE, Rothman RH, Calligaro KD, Raviola CA et al. Arterial and ischemic aspects of total knee arthroplasty. Am J Surg 1992;164(3):237-40.

17. Kumar K, Railton C, Tawfic Q. Tourniquet application during anesthesia: “What we need to know ?”. J Anaesthesiol Clin Pharmacol 2016;32(4):424-30.

18. Holmberg A, Milbrink J, Bergqvist D. Arterial complications after knee arthroplasty: 4 cases and a review of the literature. Acta Orthop Scand 1996;67(1):75-8.

19. Guo S. Is Velband still a safe and cost effective skin protection beneath the tourniquet in hand surgery? Hand Surg 2011;16(1):5-8.

20. Chen HY, Navia JA, Kassab GS. A simulation of vessel-clamp interaction: transient closure dynamics. Ann Biomed Eng 2009;37(9):1772-80.

21. Sucu S, Ozcan HÇ, Misirlioglu M, Guralp O, Kaya B. Temporary clamping of bilateral common iliac artery during cesarean hysterectomy for the management of placenta [published online ahead of print, 2020 Apr 21]. Eur J Obstet Gynecol Reprod Biol. 2020;250:188-194.

doi:10.1016/j.ejogrb.2020.04.021

\section{Tables}


Table 1

Score of endothelial injury, tunica media smooth muscle vacuolation and lamina elastica interna injury were graded as in the table and total score was obtained by summing of these scores. Total score grading; 0-3: mild injury, 4-6: moderate injury, 7-10: severe injury.

\section{Score of Endothelial Injury \\ Score of Tunica Media Smooth Muscle Vacuolation}

Score of Lamina Elastica Interna Injury

$\begin{array}{lcllll}\text { None } & 1 & \text { None } & 0 & \text { Intact } & 0 \\ \text { Minimal } & 2 & \text { Some cells in deep } & 1 & \text { Interruption/ Fissure } & 1 \\ \begin{array}{l}\text { Moderate } \\ \text { desquamation* }\end{array} & 3 & \text { Consistent } & 2 & \text { Significant Fissure } & 2 \\ \begin{array}{l}\text { Significant } \\ \text { desquamation* }\end{array} & 4 & \text { Superficial + Deep } & 3 & \begin{array}{l}\text { Significant } \\ \text { Fissure/Cavity }\end{array} & 3 \\ & & & \text { +Trombus }\end{array}$

$*_{\text {in }}$ endothelial cells.

Table 2

Artery injury parameters according to clamp, tourniquet and control groups.

\begin{tabular}{|c|c|c|c|c|c|c|}
\hline Artery & & NEC & SEI & SLEI & STMSMV & $\begin{array}{l}\text { Total } \\
\text { Score }\end{array}$ \\
\hline \multirow[t]{3}{*}{ Clamp } & Min-Max & $1-27$ & $1-3$ & $0-1$ & $0-2$ & $1-5$ \\
\hline & \multirow[t]{2}{*}{$\begin{array}{l}\text { Mean } \pm \text { SD } \\
\text { (median) }\end{array}$} & \multirow[t]{2}{*}{$\begin{array}{l}14,43 \pm 10,6 \\
(18)\end{array}$} & $\begin{array}{l}1,71 \pm \\
0,95\end{array}$ & \multirow[t]{2}{*}{$\begin{array}{l}0,29 \pm 0,49 \\
\text { (0) }\end{array}$} & \multirow[t]{2}{*}{$\begin{array}{l}1,14 \pm 0,69 \\
\text { (1) }\end{array}$} & $\begin{array}{l}3,14 \pm \\
1,46\end{array}$ \\
\hline & & & (1) & & & (3) \\
\hline \multirow[t]{3}{*}{ Tourniquet } & Min-Max & $9-30$ & $1-2$ & $0-1$ & $0-2$ & $1-4$ \\
\hline & \multirow{2}{*}{$\begin{array}{l}\text { Mean } \pm \text { SD } \\
\text { (median) }\end{array}$} & \multirow{2}{*}{ (15) } & $1,57 \pm$ & $0,43 \pm 0,53$ & $0,43 \pm 0,79$ & $2,43 \pm$ \\
\hline & & & & & & \\
\hline \multirow[t]{4}{*}{ Control } & Min-Max & $20-33$ & $0-0$ & $0-0$ & $0-2$ & $0-2$ \\
\hline & \multirow{3}{*}{$\begin{array}{l}\text { Mean } \pm \text { SD } \\
\text { (median) }\end{array}$} & $24,57 \pm 4,2$ & $0 \pm 0$ & $0 \pm 0$ & \multirow{3}{*}{$\begin{array}{l}0,43 \pm 0,79 \\
(0)\end{array}$} & \multirow{3}{*}{$\begin{array}{l}0,43 \pm \\
0,79 \\
(0)\end{array}$} \\
\hline & & $(25)$ & $(0)$ & $(0)$ & & \\
\hline & & & & & & \\
\hline
\end{tabular}


Table 3

Vein injury parameters according to clamp, tourniquet and control groups. NEC: Number of endothelial cells, SEl: Score of endothel injury, SLEl: Score of lamina elastica interna injury.

\begin{tabular}{|lllll|}
\hline Vein & & NEC & SEI & SLEI \\
\hline Clamp & Min-Max & $5-20$ & $1-3$ & $0-1$ \\
& Mean \pm SD & $12.86 \pm 5.1$ & $1.86 \pm 0.69$ & $0.57 \pm 0.53$ \\
& (median) & $(12)$ & $(2)$ & $(1)$ \\
\hline \multirow{2}{*}{ Tourniquet } & Min-Max & $9-18$ & $1-2,3$ & $0-2,3$ \\
& Mean \pm SD & $13.86 \pm 3.27$ & $1.57 \pm 0.42$ & $0.76 \pm 0.81$ \\
& (median) & $(14)$ & $(1.67)$ & $(0.67)$ \\
\hline \multirow{2}{*}{ Control } & Min-Max & $16-29$ & $0-2$ & $0-0.7$ \\
\hline & Mean \pm SD & $22.57 \pm 4.89$ & $0.71 \pm 0.95$ & $0.24 \pm 0.32$ \\
& (median) & $(22)$ & $(0)$ & $(0)$ \\
\hline
\end{tabular}

Figures 

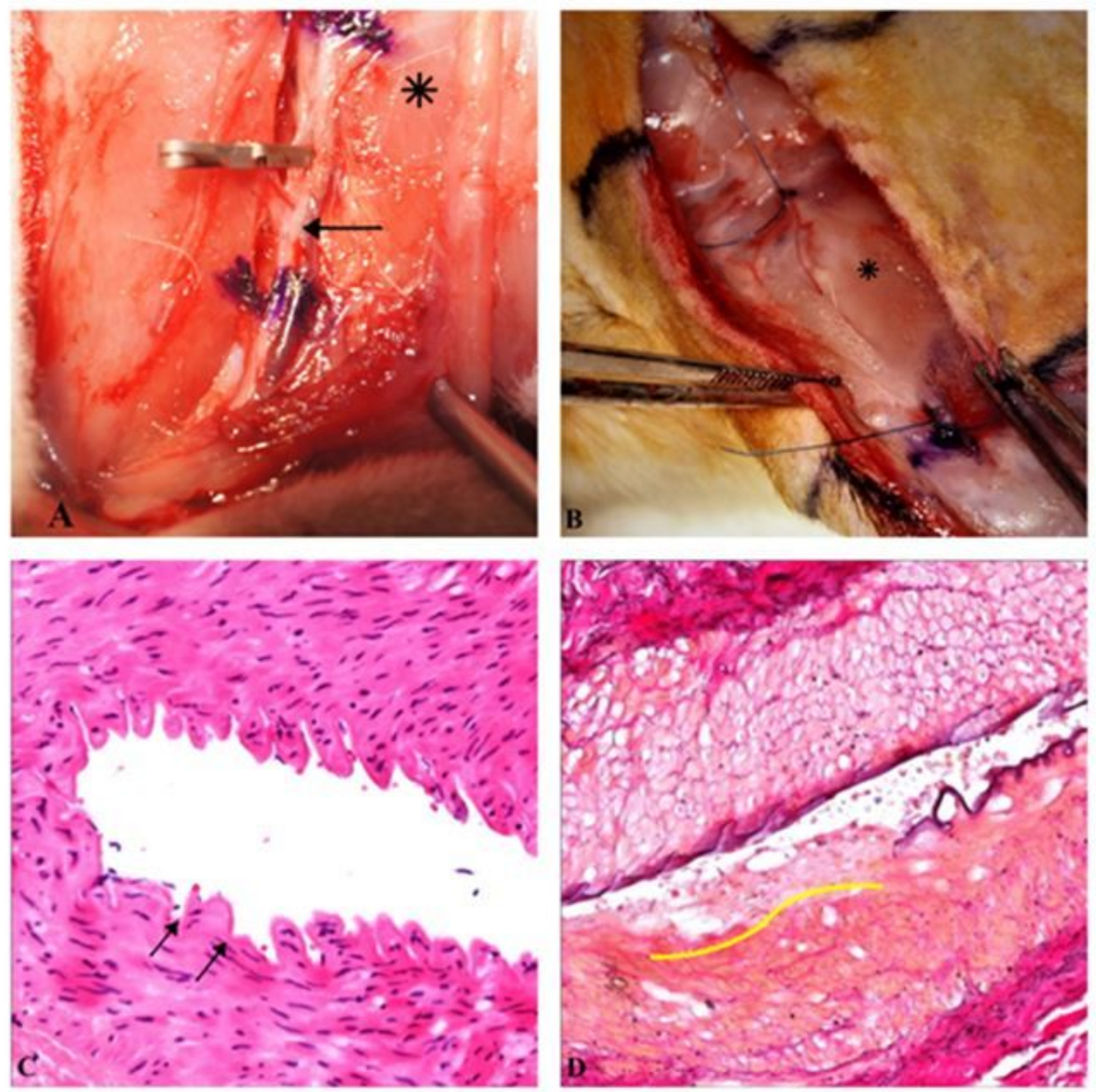

\section{Figure 1}

(1A): CFA was clamped. Black arrow: Femoral vein and nerve, Asterisk: Rectus femoris muscle, (1B): Asterisk: Rectus femoris muscle, (1C): Black arrows: Areas without endothelial cells (Hematoxylin and eosin stain, x200), (1D): Yellow line: Fibrin thrombi (Elastik Van Gieson stain, x200). 

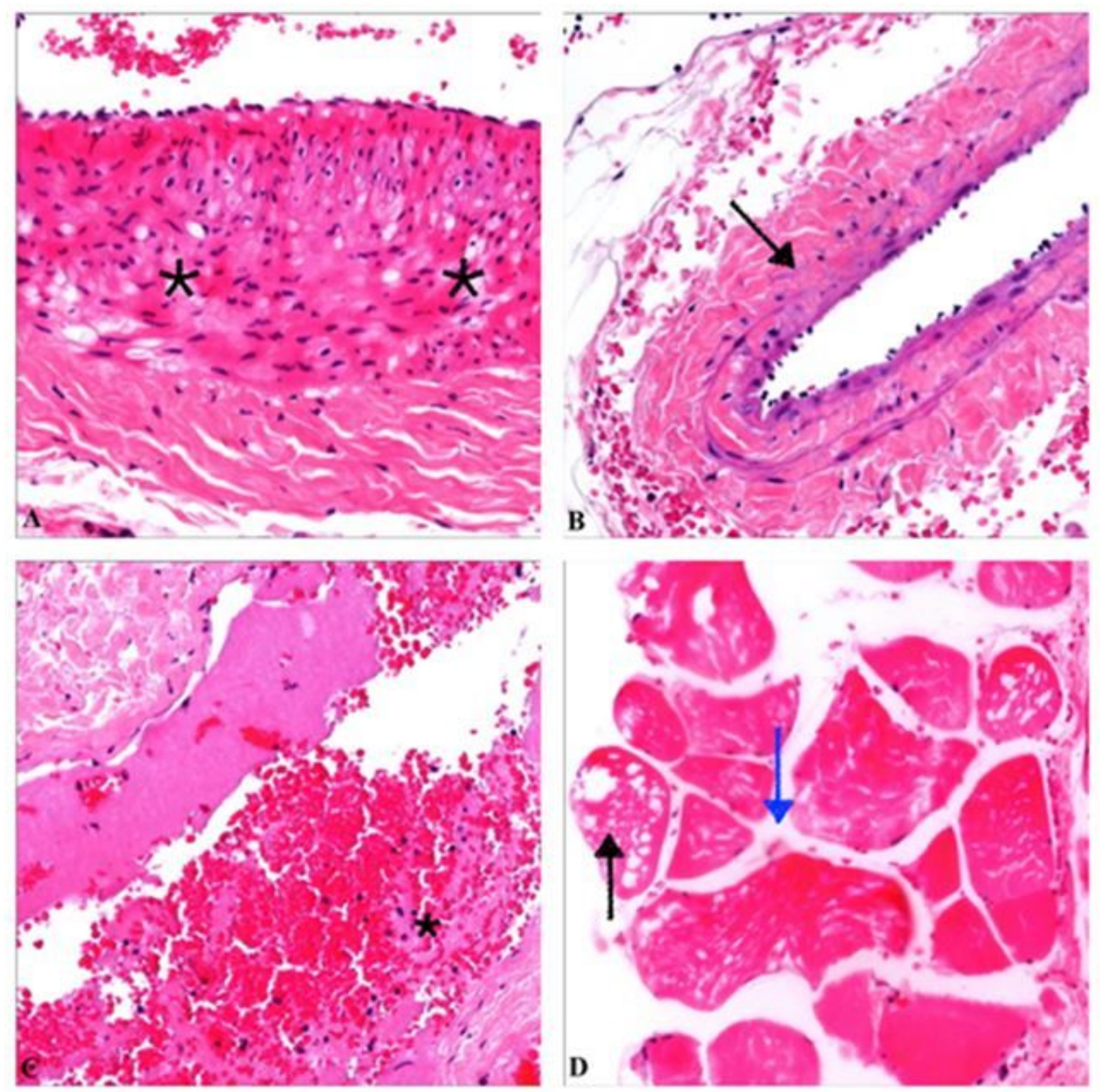

Figure 2

(2A): Black stars: Vacuoles (HE stain, x200), (2B): Severe injury, Black arrow: naked areas (HE stain, x200), (2C): Black star: Fibrin plaque (HE stain, x200), (2D): Black arrow: vacuoles with loss of cytoplasmic structures, Blue arrow: cytoplasmic eosinophilia. 
a)

Clamp group

TNF a

Beta Actin

Tourniquet group

TNF a

Beta Actin

Control group

TNF a

Beta Actin b)
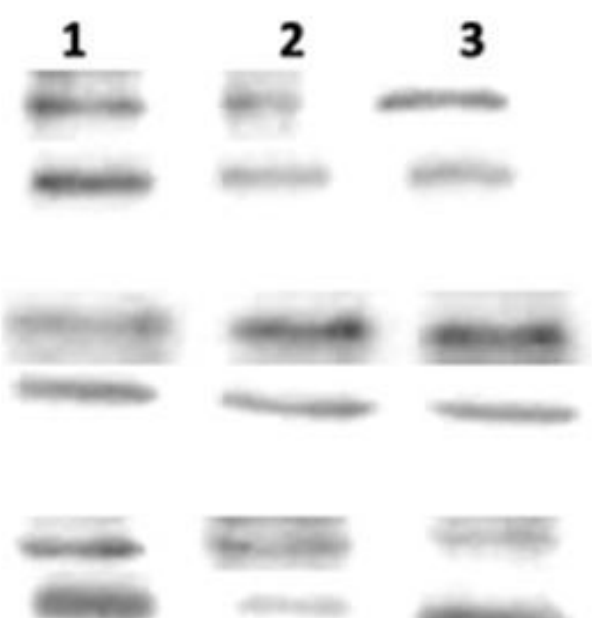

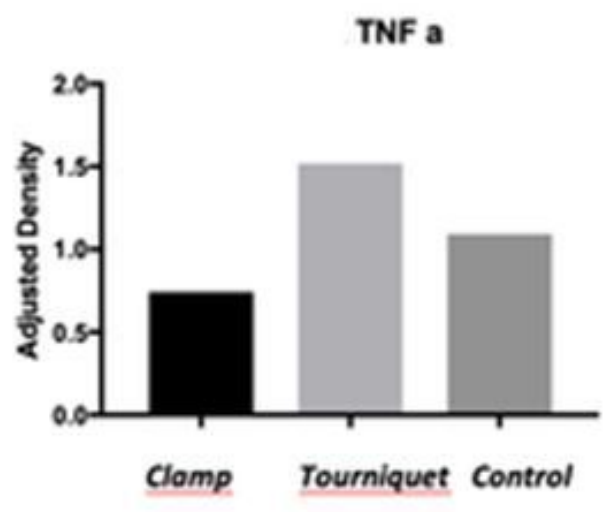

Figure 3

(3a) The expression levels of TNF-a was examined by Western blotting. Beta actin was used as equal loading control in analysis, (3b) Densitometric analysis of Western blot results. 